\title{
EFECTO DE UN ENVEJECIMIENTO ACELERADO MEDIANTE RAYOS UV EN LA PROPAGACIÓN SUPERFICIAL DE GRIETAS DE DEBOBINADO EN TABLEROS CONTRACHAPADOS DE Eucalyptus nitens
}

\section{ULTRAVIOLET RAY AGING EFFECT ON LATHE CHECK SURFACE PROPAGATION IN Eucalyptus nitens PLYWOOD}

\author{
Andrés Acevedo ${ }^{1}$, Cecilia Bustos ${ }^{1}$, Jean Pierre Lasserre², William Gacitua ${ }^{1 \star}$
}

\begin{abstract}
RESUMEN
El objetivo de este estudio fue evaluar el efecto de un envejecimiento acelerado mediante rayos ultravioleta y condiciones ambientales controladas sobre la propagación de grietas de debobinado y agrietamiento superficial, al simular las condiciones de servicio en exterior de tableros contrachapados fabricados con chapas provenientes de tres alturas de trozas de familias segregadas de Eucalyptus nitens y bajo condiciones de debobinado controladas. Para realizar el ensayo se uso una cámara de envejecimiento acelerado UV (rayos ultravioleta) capaz de reproducir el espectro de radiación emitido por el sol bajo condiciones climáticas controladas de humedad relativa, condensación y temperatura, de acuerdo a la norma ASTM G154-06. Mediante análisis de imágenes se evaluó el nivel de agrietamiento superficial porcentual en el área envejecida de las probetas, además del ancho de grietas en la superficie de los tableros. El análisis de imágenes del área envejecida de las probetas mostró que el ancho de grietas y área de agrietamiento disminuye con respecto a la altura de la troza, existiendo diferencias significativas en agrietamiento, entre familias segregadas de Eucalyptus nitens. Además las grietas de debobinado en las chapas se propagan hacia la superficie, siendo éstas responsables del agrietamiento en las caras de tableros contrachapados. Basado en los resultados del estudio, el envejecimiento acelerado mediante UV es un buen indicador para evaluar la propagación de grietas de debobinado y el agrietamiento superficial en muestras de tableros contrachapados expuestos al exterior.
\end{abstract}

Palabras claves: Grietas de debobinado, envejecimiento UV, tableros contrachapados, Eucalyptus nitens.

\begin{abstract}
The objective of this study was to evaluate the effect of accelerated aging with UV rays and controlled environmental conditions in lathe check propagation and surface cheking, simulating the conditions of outside service of plywood made with veneers from three heights of logs families segregated of Eucalyptus nitens and under conditions of controlled peeling process. To perform the test using an accelerated aging chamber UV (ultraviolet rays) can reproduce the spectrum of radiation emitted by the sun under controlled climatic conditions of relative humidity, condensation and temperature according to ASTM G154-06. By image analysis assessed the level of surface checking in the area percentage of the specimens aged in addition to the width of checks on the plywood surface. Image analysis of the aging of the specimen area showed that the width and area checks decreases with respect to the height of the log, showing significant differences in checking between segregated families of Eucalyptus nitens.
\end{abstract}

\footnotetext{
1Departamento de Ingeniería en Maderas, Universidad del Bío-Bío. Concepción, Chile. aacevedo85@gmail.com,cbustos@ubiobio.cl

${ }^{2}$ Forestal Mininco S.A. Concepción, Chile. jean.lasserre@forestal.cmpc.cl

Autor para correspondencia: *wgacitua@ubiobio.cl

Recibido: 06.01.2012. Aceptado: 16.07.2012
} 
Besides lathe checks in the veneers spread to the surface, these being responsible for the checking in the plywood surface. Based on the results of the study, UV-accelerated aging was a good indicator for evaluating the late check propagation and surface checking in samples exposed to the exterior plywood.

Keywords: Lathe checks, UV aging, plywood, Eucalyptus nitens.

\section{INTRODUCCIÓN}

Los agentes responsables de los cambios físicos en la superficie de la madera, como decoloración y agrietamiento, ocasionados por el medio ambiente son, la radiación solar (luz ultravioleta, visible e infrarroja), humedad (rocío, lluvia, nieve) y temperatura. El conjunto de estos elementos como su interacción, son puntos clave que intervienen en el proceso de envejecimiento y agrietamiento superficial de la madera. Al mismo tiempo, también influyen características propias de la madera, tales como densidad, composición física, química y anatómica influyen sobre estos cambios (Rodríguez y Fuentes 2003). La degradación superficial en la madera puesta a la intemperie es un proceso de semanas, meses e incluso años, dependiendo de varios factores como si está en estado natural, con algún tipo de recubrimiento o la posición en la que esté expuesto el material al sol, viento y lluvia.

La radiación ultravioleta, es el principal causante de la degradación de las superficies de madera y recubrimientos (Garay 2009). La luz ultravioleta transmitida por el sol inicia reacciones fotoquímicas en la superficie de la madera resultando deterioros visibles como un cambio de color por degradación de la lignina y fallas en la adhesión entre madera y recubrimientos y aumento de rugosidad de la superficie. La acción de esta degradación, tiene como resultados visibles: pérdida de brillo, cambio de matiz, laminación (ampollas), craqueo o agrietamiento y amarillamiento (Parker 1965). El cambio de color de la madera, es básicamente una reacción de superficie, no obstante, puede afectar de forma más profunda, por las reacciones derivadas de la degradación. La degradación de la madera por luz ultravioleta en tableros contrachapados, se produce a profundidades de 0,05- 2,5 mm (Feist y Hon 1984) por lo que afecta principalmente a la chapa superficial y parte de la secundaria, dañando también la unión adhesiva que mantiene pegada las chapas.

Para tableros contrachapados, la calidad de la chapa y de la adhesión, son constantes importantes cuando se habla de degradación en el tablero (Lutz 1978), especialmente para tableros de uso estructural sometidos a condiciones de uso exterior.

Por otro lado, los defectos de la chapa más recurrentes son: rugosidad, chapa espiralada, variaciones en el espesor y grietas de debobinado (Devallance et al. 2007, Devlieger et al. 1986, Marchal et al. 2009). Además, influyen en la calidad del tablero la adhesión entre las chapas, tipo de adhesivo, gramaje, prensado del tablero, etc.

En el agrietamiento en la madera durante la exposición a la intemperie, participan la lixiviación y el efecto plastificante del agua que facilitan el agrandamiento de las microgrietas. Estudios previos (Feist y Hon 1984, Rodríguez y Fuentes 2003) revelan la destrucción de la lamela media y de varias capas de la pared celular en este tipo de agrietamiento. Las fibras individuales y microfibrillas, resultan ser los elementos mas estables después de la degradación por exposición al exterior. De acuerdo a Feist y Hon (1984) dentro de las capas de la pared celular, varias de ellas tuvieron fallas por la pérdida de cohesión entre las capas. Este proceso destructivo por acción atmosférica fue limitado a la capa superficial (2-3 $\mathrm{mm})$ en madera sólida.

En estudios de agrietamientos, para madera de pino amarillo al ser sometida a envejecimiento artificial durante 500 h., se observó que en la sección transversal las células fueron separadas de la zona de la lamela media, y en casos extremos la pared celular colapsó (Rodríguez y Fuentes 2003). 
Kuéera y Sell (1987) realizaron ensayos de envejecimiento acelerado y análisis anatómico en madera aserrada de Haya (Fagus sylvatica L.). Dentro de sus observaciones mencionan la fragilidad de los radios medulares de la cara tangencial, lo que generó áreas de ruptura, atribuyéndolo principalmente al ancho del radio medular y al movimiento natural de la madera (hinchamiento y contracción). La cara transversal presentó agrietamientos, pero no con la misma intensidad. Algunas probetas mostraron agrietamientos de 8 a $10 \mathrm{~mm}$ y en casos excepcionales de hasta varios centímetros de largo. A nivel microscópico, se produjeron rupturas de las capas internas de la pared celular, generalmente la lamela media, presentándose de igual forma en vasos y fibras.

Las grietas de debobinado que aparecen por el proceso de corte mecánico, son grietas que están presentes en la chapa las cuales hacen que ésta sea mas propensa a quebrarse y generar espacios por donde el adhesivo fluye en el proceso de prensado; así, el origen del agrietamiento de las chapas en las superficies de los tableros contrachapados podría estar relacionado con grietas de debobinado así como las microgrietas presentes en las chapas.

En estudios realizados para la especie de Eucalyptus nitens, las microgrietas se producen por la concentración de esfuerzos alrededor de los vasos, las grietas se propagan por la lamela media que es más quebradiza, hasta convertirse en meso grietas visibles al ojo humano (Gacitúa et al. 2007).

El problema de agrietamiento superficial en tableros contrachapados, cuando están en servicio, es un tema que preocupa a la industria de tableros y recubrimientos ya que disminuye la vida útil del producto. El objetivo de este estudio fue evaluar las causas de este agrietamiento superficial, para mejorar procesos en el que se fabriquen tableros más resistentes y con nuevas especies como el Eucalyptus nitens.

\section{MATERIALES Y MÉTODOS}

\section{Fabricación de tableros}

Fueron utilizados árboles de Eucalyptus nitens de 13 años de edad, provenientes de un predio de Forestal Mininco S.A., de suelo arcilloso de la zona de Mulchén, ubicado en la región del Bío-Bío, Chile. Se fabricaron tableros contrachapados a escala industrial en la planta de INFODEMA S.A. (Acevedo et al. 2012), en la ciudad de Valdivia, Chile. Los tableros se fabricaron con madera proveniente de seis grupo-familia de Eucalyptus nitens, siendo denominados grupo 1 a 6 (Tabla 1), y con trozas cortadas a tres alturas provenientes de altura A (base hasta $3 \mathrm{~m}$ altura), altura B ( $3 \mathrm{~m}-6 \mathrm{~m}$ ) y altura C $(6 \mathrm{~m}-9 \mathrm{~m})$. Sólo con las familias codificadas como 2831 del Grupo 1 y 2744 del Grupo 6 se fabricaron tableros con trozas de la altura $\mathrm{C}$, ya que sólo para estas familias se logro obtener trozas de altura mayor a los $6 \mathrm{~m}$, con diámetros superior a los $28 \mathrm{~cm}$ para el proceso de debobinado.

Con tableros contrachapados de Eucalyptus nitens, fabricados con 5 chapas de 1,8 mm de espesor, utilizando adhesivo fenol formaldehído (Oximix 2217, proporcionado por Oxiquim S.A.), se evaluó la cara superficial; las chapas se obtuvieron de un proceso de debobinado controlado, utilizando una tasa de compresión $\mathrm{TC}=5,0 \%$ (Acevedo et al. 2012).

Fue incluido el análisis de agrietamiento superficial por exposición UV, tableros fabricados con trozas basales desde árboles de la familia 2820 de procedencia Toroongo y raza South CentVic, a diferentes tasas de compresión $(0,5 \%, 3,5 \%$ y $5,0 \%)$. La familia procedencia que se utilizó para pruebas de tasa de compresión, correspondió a la familia que dió mejores resultados en términos de bajo agrietamiento en estudios previos (Valenzuela et al. 2011). 
Tabla 1. Procedencia, raza y codificación de familias de Eucalyptus nitens.

\begin{tabular}{|c|l|l|l|l|}
\hline Grupo N & Código & Familia & Procedencia & Raza \\
\hline TC & 11 & 2820 & Toorongo & South CentVic \\
\hline 1 & 12 & 2831 & Toorongo & South CentVic \\
\hline 2 & 21 & 2727 & Rubicon Snobs Ck Rd & North CentVic \\
\hline 3 & 31 & 2777 & Macalister & North CentVic \\
\hline 4 & 41 & 2846 & Toorongo Plateau & South CentVic \\
\hline 5 & 51 & 2790 & MT Tanglefoot & South CentVic \\
\hline 6 & 61 & 2744 & Rubicon & North CentVic \\
\hline
\end{tabular}

Nota: Ejemplos; el código 11: primer numero (1) Grupo $\mathrm{N}^{\mathrm{o}} 1$ y segundo número (1) familia 1 en la tabla, (2820); el código 51: primer número (5) Grupo $\mathrm{N}^{\circ} 5$ y segundo número (3) familia 3, en la tabla (2790).

\section{Probetas}

Probetas de tres tableros seleccionados aleatoriamente (3 réplicas de c/u) fueron cortadas, para cada familia y altura de dimensiones $7,2 \times 15 \mathrm{~cm}$ desde tableros fabricados en planta, esto es para cada tasa de compresión y grupo-familia; las probetas se fijaron en una cámara de envejecimiento UV (QUV LU-0819.2, modelo QUV/spray) (Figura 1-b), dejando expuesta a los rayos UV y a humedad la cara de mejor apariencia visual; la cual se consideró la cara menos rugosa y con menos presencia de vasos cortados transversalmente. Las dimensiones del área expuesta fueron de $6,5 \times 10 \mathrm{~cm}$. (Figurs 1_a)

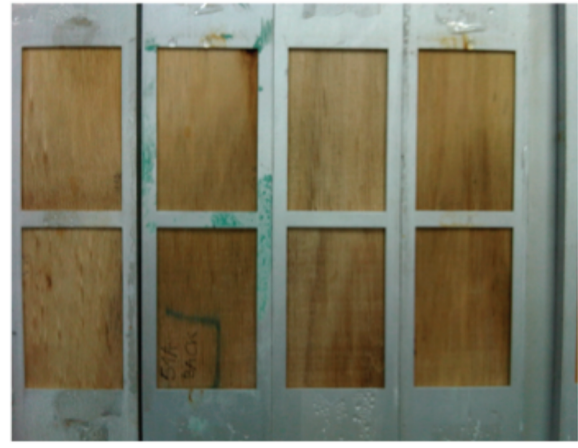

(a)

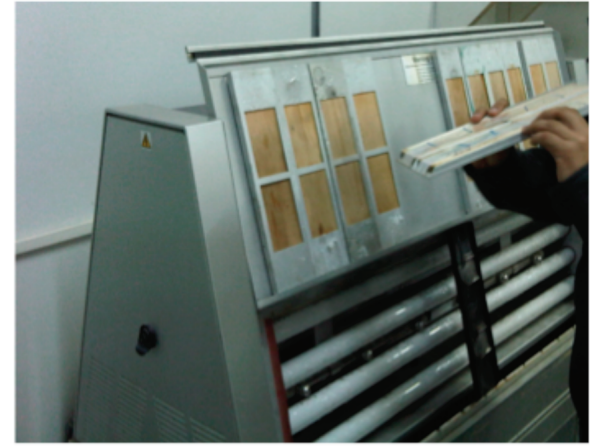

(b)

Figura 1. (a) zona de envejecimiento para probetas de plywood; (b) cámara de envejecimiento UV

\section{Cámara de Envejecimiento UV}

Utilizando una cámara de envejecimiento acelerado marca QUV LU-0819.2 modelo QUV/spray con Solar Eye (control de radiación) y lámparas UVA-340 (Figura 1-b).

Este envejecimiento acelerado mediante rayos UV, fue realizado usando como pauta la norma ASTM G154: Standard practice for Operating fluorescent light Apparatus for UV exposure of nonmetallic materials. La radiación de la luz del sol al mediodía de verano es alrededor de $0,68 \mathrm{~W} / \mathrm{m}^{2} / \mathrm{nm}$, que corresponde a la mayor radiación que podría estar expuesta la madera naturalmente. Para alcanzar un envejecimiento en menos tiempo y resultados más rápidos se calibro la luz del equipo a $0,95 \mathrm{~W} / \mathrm{m}^{2} / \mathrm{nm}$ durante el ciclo (Figura 2), siendo un $40 \%$ mayor al espectro natural. 


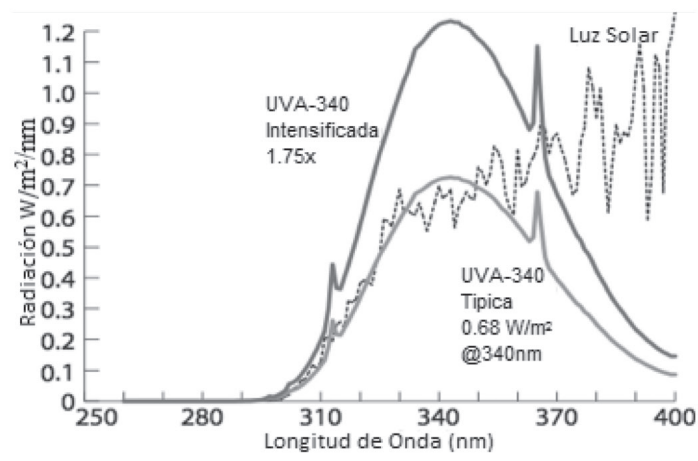

Figura 2. Curvas de intensidad de radiación en comparación a radiación de luz solar. (Fuente: Manual QUV/spray )

Las probetas se dejaron en envejecimiento $96 \mathrm{~h}$. continuas (ASTM G154-06), divididos en ciclos de 12 h. Se repitió cada ciclo 8 veces, el cual se detalla en la tabla 2.

Tabla 2. Etapas del ciclo (12 horas) de envejecimiento UV.

\begin{tabular}{|l|l|c|}
\hline Etapas & Temperatura & Tiempo (h) \\
\hline 1) Luz UV & $60^{\circ} \mathrm{C}\left(-+3{ }^{\circ} \mathrm{C}\right)$ & 8 \\
\hline 2) Spray (agua) & $20^{\circ} \mathrm{C}\left(-+3{ }^{\circ} \mathrm{C}\right)$ & 0.25 \\
\hline 3) Condensación & $40^{\circ} \mathrm{C}\left(-+3{ }^{\circ} \mathrm{C}\right)$ & 3.75 \\
\hline
\end{tabular}

Luego de finalizado el envejecimiento, las probetas terminaron completamente saturadas debido al proceso de spray y condensación final que se aplicó según la norma; por lo tanto, y para una mejor observación de las grietas superficiales en los tableros, se procedió a secar las probetas hasta una humedad de $12 \%$, base seca (condiciones de secado: $63{ }^{\circ} \mathrm{C}$ por 12 horas).

\section{Captura de imágenes}

Después del proceso de acondicionamiento de las probetas a un contenido de humedad del $12 \%$, se procedió a la captura de imágenes para su posterior análisis. Las imágenes fueron capturadas en color y sin magnificación, mediante una cámara digital de alta resolución (PANASONIC DMC-FZ8) empotrada en un trípode para impedir cambios en la posición y altura en la toma de fotografías digitales, la captura de imágenes se realizó usando iluminación constante, mediante ampolletas de luz corriente (amarilla), con iluminación en $360^{\circ}$; se obtuvieron imágenes de 2048 x 1536 pixeles para cada una de las probetas.

\section{Selección de área representativa y análisis de imágenes:}

Con las imágenes ya cargadas en un ordenador, se procedió al análisis de imágenes mediante el software Image Pro Plus 6.2. Seleccionando un área representativa de $601 \times 901$ pixeles o 6.5 x $10 \mathrm{~cm}$., que corresponde al área envejecida en la superficie del tablero (Figura 3-a). 


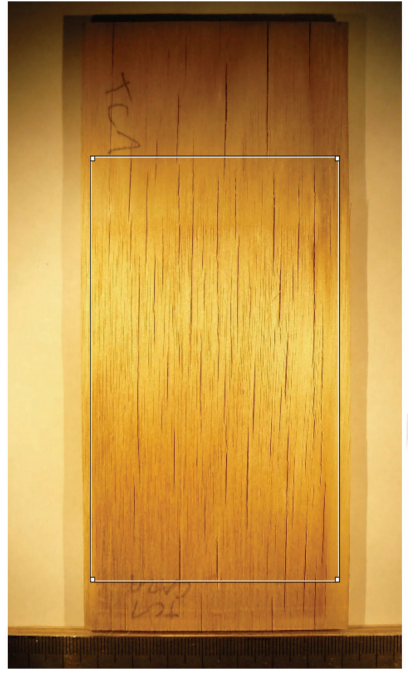

(a)

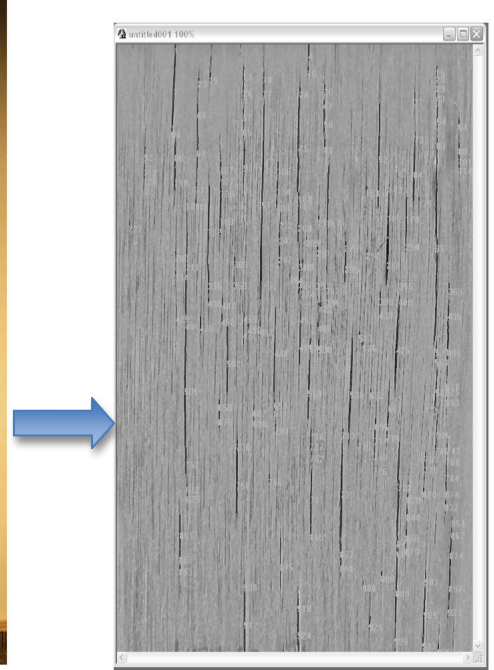

(b)

Figura 3. (a) selección de área representativa; (b) medición de parámetros (escala de grises).

Con el área representativa ya delimitada, se procede a aplicar un filtro de contraste, para dejar el área seleccionada en escalas de grises facilitando así la medición y el análisis de las grietas (Figura 3-b).

\section{Medición de ancho y porcentaje de grietas}

Con el área representativa ya filtrada en escala de grises, se procede a identificar las grietas, midiendo el ancho (pixeles) y área de grietas $\left(\mathrm{pix}^{2}\right)$ en el área representativa seleccionada mediante la aplicación de filtros de contraste y relieve usando el software Image Pro Plus 6.2, automáticamente en la opción "select measurement" se selecciona la opción de ancho y área (Figura 4), exportando los resultados a una planilla Excel para el posterior cálculo de promedio de anchos y sumatoria de áreas de grietas.

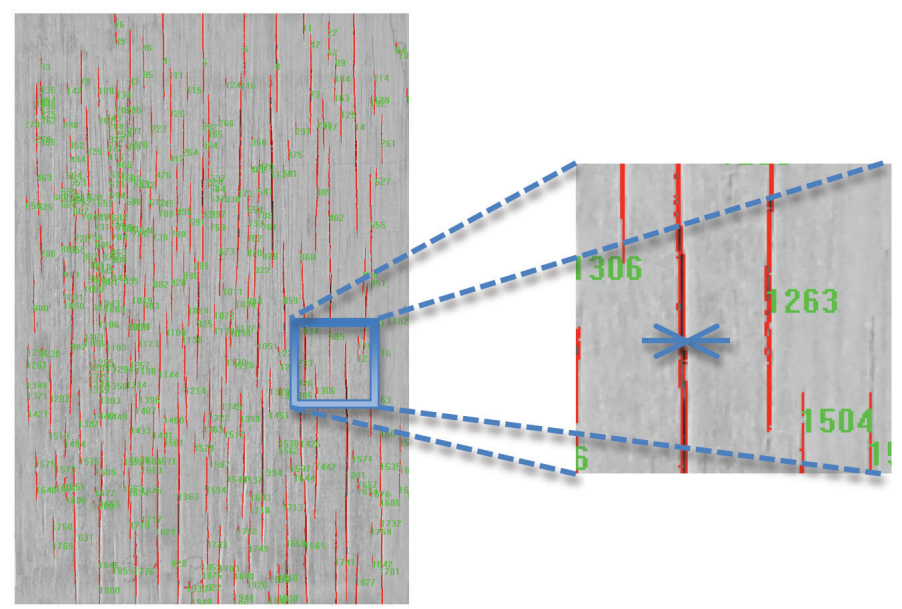

Figura 4. Selección y medición de ancho-área de grietas, magnificación de ancho de grieta (Image pro Plus 6.2). 
Luego, se obtiene el ancho promedio de grietas (pix). Para el parámetro porcentaje de grietas, se mide el área total de grietas $\left(\mathrm{pix}^{2}\right)$, es decir, se suman las áreas entregadas por el software, y se divide por el área total envejecida $(601$ x 901 pix ó 6,5 x $10 \mathrm{~cm})$. Todas las mediciones están en pixeles, las cuales se transformaron a milímetros usando una regla milimétrica fotografiada con la misma magnificación.

\section{RESULTADOS Y DISCUSIONES}

El análisis de imágenes realizado a la superficie de los tableros con respecto al ancho de grietas (mm), para los 6 grupos, familias y alturas de Eucalyptus nitens se muestra en la figura 5. Se observa disminución en el ancho promedio de las grietas en tableros de la familia 2831 del grupo $\mathrm{N}^{\mathrm{o}} 1$ (l 12 ) con respecto a la altura de la troza, donde se da una diferencia significativa (ANOVA, $p<0,05$ ) entre el ancho de grieta tablero proveniente de la troza C $(3-9 \mathrm{~m})$ respecto a la troza A (base $-3 \mathrm{~m}$ ). Para

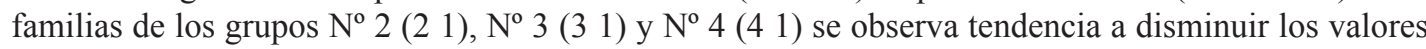
con respecto al aumento de la altura, pero no se observan diferencias significativas (ANOVA, $p>0,05$ ) entre las familias de estos tres grupos.

Existe un mayor ancho de grietas para tableros de familias del grupo $\mathrm{N}^{\circ} 5(51)$ y $\mathrm{N}^{\mathrm{o}} 6(61)$, familias 2790 y 2744 respectivamente, donde los tableros provenientes de alturas A (base- $3 \mathrm{~m})$ y B $(3-6 \mathrm{~m})$ están sobre el valor promedio para el ancho de grieta total. Por otro lado, se observó que el resultado de promedio de ancho de grieta para tablero proveniente de la troza C $(6-9 \mathrm{~m})$ para la familia 2744 perteneciente al grupo $\mathrm{N}^{\circ} 6(6 \mathrm{1C})$ tiene los valores más bajos, pudiendo deberse a que la sección chapa usada en la superficie tenia mayor densidad, menor frecuencia y largo de grietas de debobinado, por lo que estas se propagaron en baja proporción a la cara del tablero. Los grupos de mayor agrietamiento 5 y 6 , corresponden con los que fueron segregados en investigaciones previas (Valenzuela et al. 2011), donde los niveles de agrietamiento también disminuyen respecto a la altura del árbol.

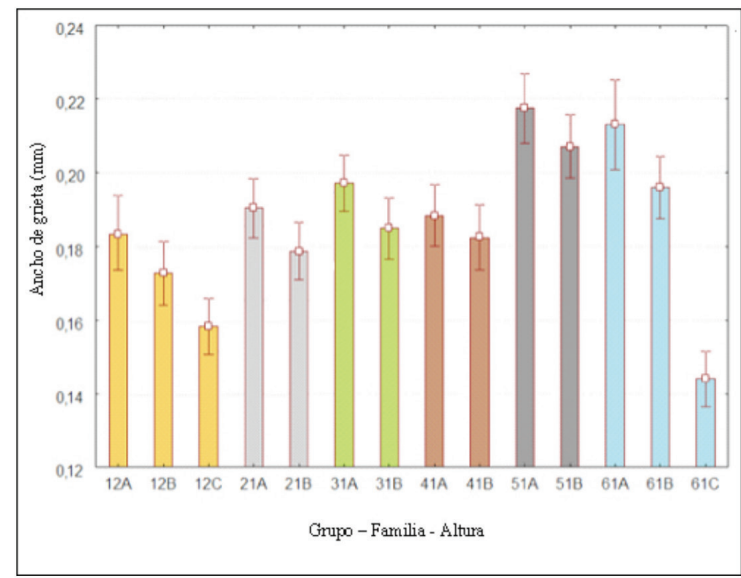

Figura 5. Intervalo de confianza para el ancho promedio de grietas superficiales de tableros $(\mathrm{mm})$, para Grupo-familia y altura $(\mathrm{A}=$ base $-3 \mathrm{~m}, \mathrm{~B}=3-6 \mathrm{~m}$ y $\mathrm{C}=6-9 \mathrm{~m})$ (confianza: $95 \%$ ).

Los resultados para el porcentaje de grietas en los 6 grupos o familias-procedencias y diferentes alturas en el árbol, son mostrados en la figura 6. 


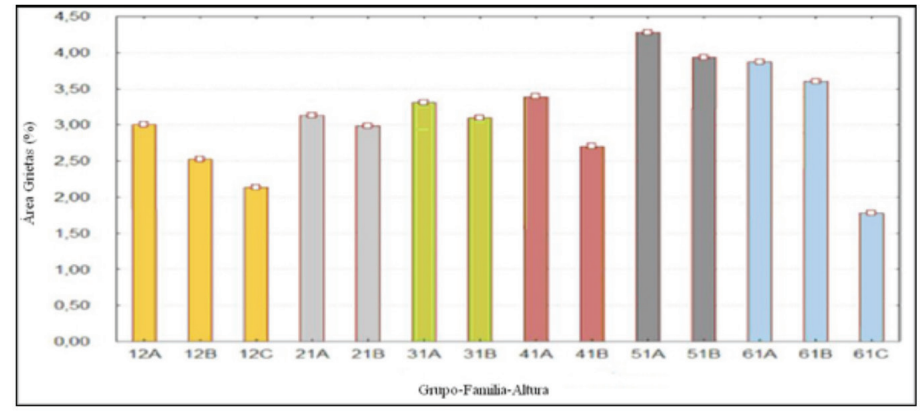

Figura 6. Porcentaje de grietas respecto al área representativa $(\%) \mathrm{v} / \mathrm{s}$ grupo-familia-altura $(\mathrm{A}=$ base $-3 \mathrm{~m}, \mathrm{~B}=3-6 \mathrm{~m}$ y $\mathrm{C}=6-9 \mathrm{~m})$.

De los resultados de porcentaje de agrietamiento (Figura 6), se observa que para todos los grupos, el porcentaje total de agrietamiento superficial en el tablero baja respecto a la altura de donde se obtuvieron las chapas para fabricarlo, siendo los resultados más bajos para la familia 2831 del grupo $\mathrm{N}^{\circ} 1$ altura B y C (12B-12C), además de las muestras pertenecientes a tableros de la familia 2744 del Grupo $\mathrm{N}^{\mathrm{o}} 6$ altura $\mathrm{C}\left(\begin{array}{l}6 \\ 1 \mathrm{C}\end{array}\right)$, donde el porcentaje de agrietamiento promedio es el menor del total de ensayos realizados.

Los resultados corroboran que al obtener chapas de alturas superiores a los $3 \mathrm{~m}$. en árboles de Eucalyptus nitens los tableros contrachapados tienen menor nivel de agrietamiento superficial (Shelbourne et al. 2002, Leandro et al. 2008, Valenzuela et al. 2011) por tener menores dimensiones en largo, área y profundidad, por lo que hay menor nivel de propagación de grietas de debobinado.

Los resultados del efecto de la tasa de compresión (TC1, TC2 y TC3) sobre el ancho de las grietas superficiales en tableros, se muestran en la figura 7. Se corrobora que al utilizar una tasa de compresión mayor ( $\mathrm{TC} 3=5 \%$ ), las grietas de debobinado tienen menores dimensiones evidenciando una propagación significativamente reducida respecto a TC1 y TC2, ya que la grieta no logra traspasar el espesor completo de la chapa y desplegarse para dañar la superficie del tablero.

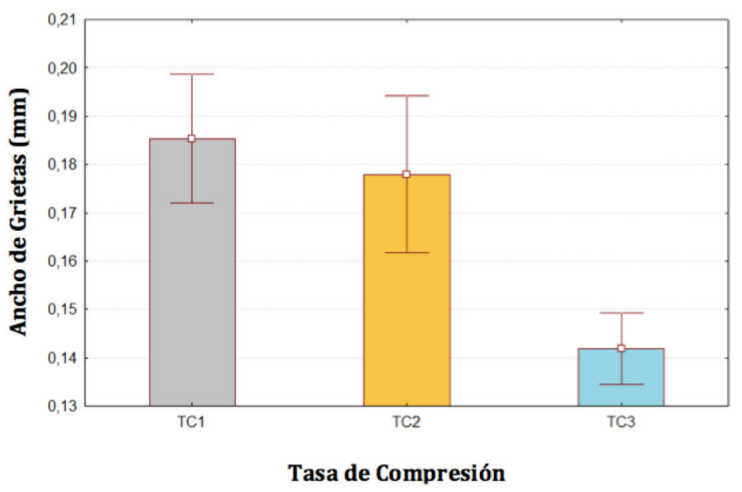

Figura 7. Intervalo de confianza para ancho promedio de grietas superficiales $(\mathrm{mm})$ de tableros, para las 3 tasas de compresión ( $\mathrm{TC} 1=0,5 \%$; $\mathrm{TC} 2=3,5 \%$; $\mathrm{TC} 3=5,0 \%$ ) (Confianza: 95\%).

Los resultados para el porcentaje de grietas respecto del área representativa (área envejecida) para las tres tasas de compresión se muestran en la figura 8 , evaluadas mediante el software de análisis de imágenes Image Pro Plus 6.2. 


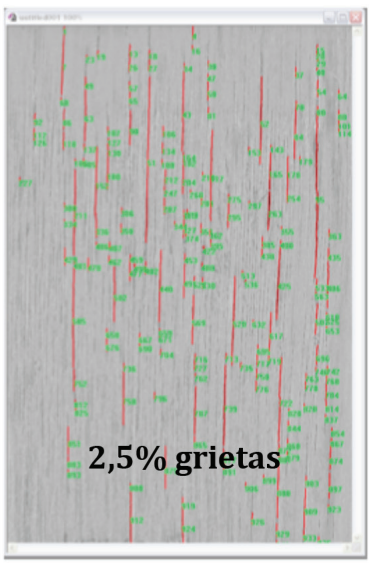

(a)

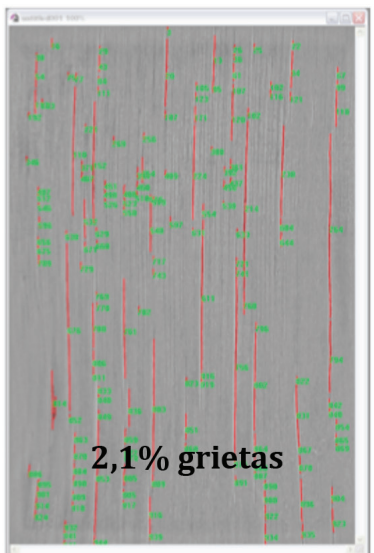

(b)

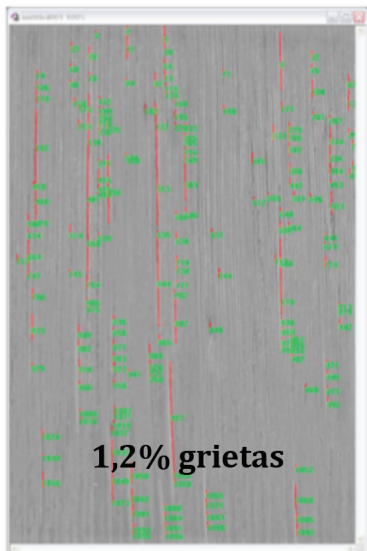

(c)

Figura 8. Imagen comparación del efecto de la TC en el porcentaje de grietas superficiales. Las letras a, b y c representan las tasas de compresión de $0,5 \%, 3,5 \%$ y $5,0 \%$, respectivamente.

Se obtuvieron imágenes de las grietas de debobinado propagadas hacia la superficie de la chapa, produciendo el agrietamiento superficial de la cara del tablero (Figura 9). Se utilizó un estereomicroscopio NIKON SMZ1000, equipado con cámara digital MicroPublisher 3.3 RTV y software de captura de imágenes QCapture Suite. En la captura de imágenes se utilizó una magnificación de 8x.

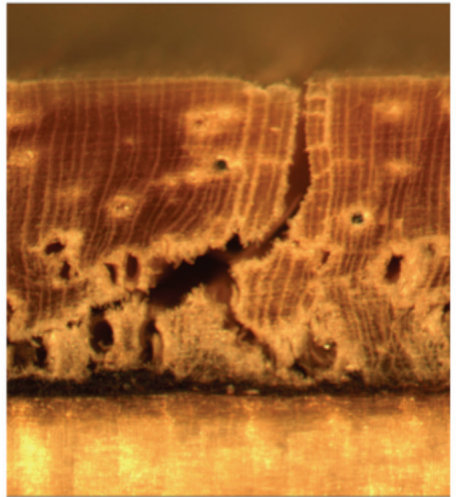

(a)

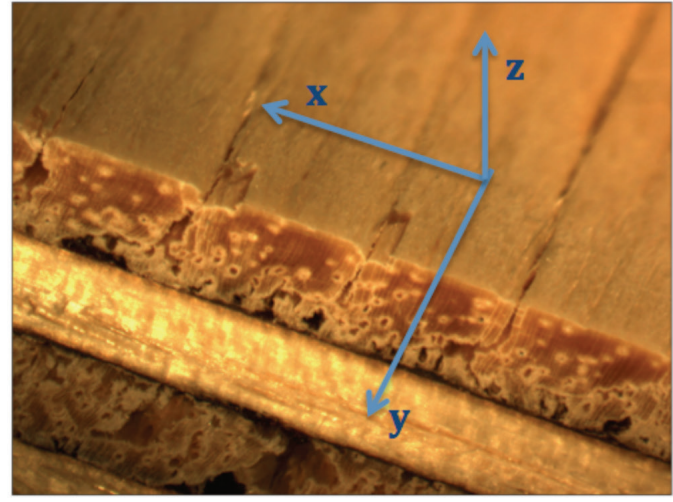

(b)

Figura 9. (a) Propagación de grieta de debobinado hacia la superficie en el espesor de la chapa

(b) Propagación de grietas de debobinado en perspectiva, y agrietamiento superficial en la cara del tablero.

De acuerdo a estos hallazgos es dable establecer que es mejor utilizar chapas de Eucalyptus nitens, obtenidas a mayores alturas en el árbol, el agrietamiento superficial de los tableros disminuye, condición que permite fabricar tableros de mejor calidad a partir de esta especie. El inconveniente desde el punto de vista de explotación del recurso, radica en la dificultad de obtener trozas de diámetros mayores a $30 \mathrm{~cm}$ (requerimiento de plantas de debobinado) a medida que aumenta la altura de aprovechamiento comercial. Las trozas utilizadas provienen de árboles de Eucalyptus nitens de 13 años de edad, para obtener trozas de mayor diámetro se necesitarían árboles de edades más avanzadas. 
Los resultados de envejecimiento UV, para las muestras de tableros provenientes del proceso de debobinado donde la tasa de compresión (TC1, TC2 y TC3) fue la variable independiente, se observó que el ancho de grieta promedio disminuyó significativamente cuando aumentó la tasa de compresión (Figura 8). La TC1 entregó un porcentaje de agrietamiento de 2,5\% y la TC2 un 2,1\%, valores que no difieren significativamente entre sí, por otro lado la TC3 mostró un porcentaje de agrietamiento 1,2 $\%$, el cual difiere significativamente de las otras dos tasas de compresión.

Con las imágenes obtenidas mediante microscopía (Figura 9), se encontró que las grietas de debobinado se propagan en el espesor de la chapa y hacia la superficie de un tablero contrachapado, cuando éste es sometido a un envejecimiento acelerado mediante UV produciendo un daño superficial en la primera chapa del tablero siendo resultados similares a los encontrados por (Rodríguez et al. 2003, Garay 2009) respecto al agrietamiento superficial en madera, cuando es expuesto a intemperie y rayos ultravioleta.

Usar maderas de mayor densidad es una ventaja ante el deterioro UV, ya que a mayor densidad el deterioro y agrietamiento es menor. A mayor densidad, menor cantidad de material erosionado, esto mismo es aplicable a la proporción de madera tardía y temprana dentro de una pieza de madera cuando se debobina una troza para la obtención de chapas.

La superficie tangencial, propiamente la zona de radios medulares, es susceptible a agrietarse cuando es sometida a los efectos de la intemperie maderas siendo congruente con resultados de otros investigadores (Rodríguez et al. 2003, Gacitúa et al. 2007)

Debido a que una chapa contiene sectores de madera tardía y madera temprana se produce un agrietamiento no homogéneo, por lo que en un mismo tablero hay zonas más agrietadas en la cara que esta expuesta a la intemperie y rayos UV.

\section{CONCLUSIONES}

De los resultados obtenidos, relacionados con el efecto de un envejecimiento UV en la calidad de tableros de familias segregadas de Eucalyptus nitens, se puede concluir que el análisis de fotografías e imágenes es una buena herramienta de medición del agrietamiento superficial en tableros contrachapados.

El envejecimiento acelerado mediante rayos UV y condiciones ambientales controladas, solo afecta a la primera chapa, esto es para las condiciones de envejecimiento usadas en este estudio; por lo tanto, el uso de una chapa de mejor calidad en las caras reduciría el agrietamiento.

Obtener chapas provenientes de trozas a mayor altura en el árbol (sobre los 3 metros) permite menores niveles de agrietamiento en la superficie de tableros contrachapados fabricados con Eucalyptus nitens.

Las familias segregadas usadas en este estudio tuvieron un buen comportamiento ante el envejecimiento UV, especialmente los tableros procedentes de alturas mayores a los 3 metros pertenecientes a la familia 2831 (Grupo $\mathrm{N}^{\mathrm{o}}$ 1), pues tienen niveles de agrietamiento bajo, disminuye la propagación de grietas de debobinado por tener áreas y dimensiones menores. La propagación de grietas de debobinado y por ende el agrietamiento superficial en las caras de tableros contrachapados de Eucalyptus nitens es un problema que puede ser minimizado, utilizando una tasa de compresión de 5\%. Con una chapa mas apretada, la frecuencia y profundidad de grietas de debobinado es menor, por lo que, el agrietamiento superficial disminuye considerablemente. 
Las grietas de debobinado son las causantes del agrietamiento superficial en tableros contrachapados de Eucalyptus nitens por el efecto de propagación de éstas, según los resultados obtenidos en este estudio, ésto combinado con las grietas características de esta especie, producidas por la liberación de tensiones de crecimiento y propagación de microgrietas, hacen primordial que se realicen más pruebas e investigación en chapas y tableros provenientes de madera de Eucalyptus nitens, tales como pruebas a mayores tasas de compresión, desarrollo de programas de secado ajustados a los niveles de agrietamiento de las familias estudiadas y pruebas de envejecimientos bajo condiciones ambientales reales.

El envejecimiento acelerado mediante rayos ultravioleta es un buen método para evaluar la propagación de grietas de debobinado y el agrietamiento superficial en muestras de tableros contrachapados, cuando son sometidos a condiciones emulando la intemperie.

\section{AGRADECIMIENTOS}

Los autores de este documento agradecen al Proyecto Fondef D07i1101 por proveer el equipamiento para desarrollar la investigación, Forestal Mininco por la donación de la materia prima, empresa Oxiquim S.A. por proporcionar resina y empresa Infodema por facilitar sus instalaciones donde se desarrollaron las pruebas.

\section{REFERENCIAS}

Acevedo, A.; Bustos, C.; Lasserre, J. P; Gacitua, W. 2012. Efecto de la Tasa de Compresión en la morfología de grietas de debobinado en chapas de Eucalyptus nitens. Maderas. Ciencia y Tecnología 14(3):289-301.

ASTM, American Society for Testing and Materials. 2006. Standard practice for Operating fluorescent light Apparatus for UV exposure of nonmetallic materials. ASTM G154.

Devallance, D. V.; Funck, J. W.; Reeb, J. E. 2007. Douglas-fir plywood gluebond quality as influenced by veneer roughness, lathe checks, and annual ring characteristics. Forest Products Journal 57 (1-2): 21-28.

Devlieger, F.; Cuevas, H.; Inzunza, L. 1986. Efecto de las variables de debobinado en pino oregón $y$ ciprés lucitánico. Bosque 7(2): 115-120.

Feist, W. C.; Hon David, N. 1984. Chemistry of Weathering and Protection. In Rowell, Roger M., ed. The Chemistry of solid Wood. Advances in chemistry series 207, Washington, DC: American Chemical Society; Chapter 11.

Gacitúa, W.; Ballerini, A.; Lasserre, JP.; Bahr, D. 2007. Nanoindentaciones y ultraestructura en madera de Eucalyptus nitens con micro y meso grietas. Maderas. Ciencia y Tecnología 3 (9): 259-270.

Garay, R. M. 2009. Efectos de dos Protectores Superficiales en las Propiedades de Tableros de Madera después de un Año de Exposición a la Intemperie. Información Tecnológica 20(4): 123-130.

Kuèera, L.; Sell, J. 1987. The weathering of wood rays in beech wood area. Holz als Roh- und Werkstoff 45: 89-93. 
Leandro, L.; Ananías, R.; Cloutier, A.; Díaz-vaz, JE.; Bermedo, M.; Sanhueza, R.; Lasserre, J.P. 2008a. Estudio preliminar de las grietas internas dentro de los anillos de madera inicial y su relación con algunas características de la estructura anatómica y la densidad en Eucalyptus nitens. Interciencia 33(11): 829-834.

Lutz, J. 1978. Wood Veneer: Log Selection, Cutting and Drying. Forest Service, US Department of Agriculture. Washington D.C.

Marchal, R.; Mothe, F.; Denaud, L. E.; Thibaut, B.; Bleron, L. 2009. Cutting forces in wood machining - Basics and applications in industrial processes. A review. Holzforschung 62(2):157-167.

Parker, H. 1965. Tecnología de recubrimiento de superficies. Wayne Detroit University, Michigan.

Q-LAB CORPORATION. 2006. Manual QUV/Spray, Accelerated Weathering Tester. Especifications LU-0819.2 Westlake, OH, USA.

Rodrigez, R.; Fuentes, F. 2003. Factores que intervienen en el proceso de envejecimiento de la madera. Revista Chapingo: Serie Ciencias Forestales y del Ambiente 9(1): 95-100.

Shelbourne, C.; Nicholas, I.; Mckinley, R.; Low, C.; Mcconnochie, R.; Lausberg, M. 2002. Wood density and internal checking of young Eucalyptus nitens in New Zealand as affected by site and height up the tree. New Zeal. J. Forest. Sci. 32: 357-379.

Valenzuela, P. 2011. Fracturas, propiedades nanomecánicas y anatomía de familias de Eucalyptus nitens. Tesis de Magíster en Ciencia y Tecnología de la Madera, Universidad del Bío-Bío, Concepción, Chile. 